\title{
Laser Thermal Ablation of Thyroid Benign Nodules
}

\author{
Mohammad Karim Shahrzad* \\ Laser Application in Medical Sciences Research Center, Shohada Tajrish Medical Center, Shahid Beheshti University \\ of Medical Sciences, Tehran, Iran
}

\section{*Correspondence to \\ Mohammad Karim Shahrzad \\ MD; Laser Application in Medical \\ Sciences Research Center, Shohada \\ Tajrish Medical Center, Shahid \\ Beheshti University of Medical \\ Sciences, Tehran, Iran. \\ Tel: +98-2122723264; \\ Fax: $+98-2122723264$ \\ Email: mk_shahrzad@yahoo.com}

Published online 27 October 2015

\begin{abstract}
Thermal ablation therapies for benign thyroid nodules have been introduced in recent years to avoid the complications of traditional methods such as surgery. Despite the little complications and the reportedly acceptable efficacy of thermal ablation methods, quite few medical centers have sought the potential benefits of employing them. This paper provides an introduction to the literature, principles and advances of Percutaneous Laser Ablation therapy of thyroid benign nodules, as well as a discussion on its efficacy, complications and future. Several clinical research papers evaluating the thermal effect of laser on the alleviation of thyroid nodules have been reviewed to illuminate the important points. The results of this research can help researchers to advance the approach and medical centers to decide on investing in these novel therapies.
\end{abstract}

Keywords: Laser; Thyroid Nodules; Thyroid gland.

\section{Introduction}

Nodular thyroid disease is commonly found in adult populations, especially in females and the elderly. It can be detected in $3 \%-7 \%$ by palpation and $20 \%-76 \%$ by ultrasonic devices, ${ }^{1-3}$ and has had an estimated growth of $5 \%$ in each year. ${ }^{4}$ Thyroid nodules are different in their shape, size, content, echogenicity, echotexture, presence of calcifications, margins, vascularity, and elastosonography. They may also be several in number in a thyroid goiter. Endocrinologists may classify them as malignant, suspicious for malignancy, borderline, probably benign, and benign, ${ }^{2}$ with a malignancy rate of $5 \%-15 \%$ which depends on age, gender, radiation exposure and family backgrounds. ${ }^{4,5}$ No special treatment do most of benign thyroid nodules require, however, pressure symptoms or cosmetic reasons may call for a therapy. ${ }^{1,3,6,7}$

\footnotetext{
Method

This paper reviews the major treatment methods that have been administered for this disease, with a special concern to the laser thermal ablation method, describing its history, process, efficacy, cost analysis and a comparison to the other methods. To provide this, several published papers in the area of treatment of benign thyroid nodules were reviewed, then the reference list from selected papers were examined to find older relevant reports, and once again, those papers that have cited the selected pioneer studies were examined to collect the most recent information about thermal ablation methods. A total amount of about 130 papers were examined, with a full-text review of 25 reports on thermal ablation therapies of benign thyroid
}

nodules, with emphasis on both the completeness and novelty of the selected papers.

\section{Treatment Methods}

Several treatment methods have been suggested and performed to date: Surgery, suppression of thyroid-stimulating hormone (TSH) with levothyroxine, and radioactive iodine as the traditional technics, and ethanol ablation, radiofrequency ablation (RFA), laser ablation and microwave ablation (MWA) as the new percutaneous ablation therapies, a glance of which is provided in this section.

\section{Surgery}

As the standard therapy, surgery has been known to be the most effective, and consequently, the most common treatment for thyroid nodules. It is reasonably safe, and can be done in many surgical centers, although a thyroid unit and a specialist may be needed in the case of complications. Compared to the other treatment methods of thyroid nodule, surgery has been always higher in the risk of complications, that is, complications are seen in $2 \%$ to $10 \%$ of patients, and it is considerably more expensive. ${ }^{8,9}$ Long hospitalization, scar formation, iatrogenic hypothyroidism, and difficulty in reoperation can be mentioned as the most common drawbacks of surgery, ${ }^{3}$ and patients with previous lobectomies, or those who are to undergo reoperations, are so exposed to morbidity or complications that their eligibility for surgery can be extremely limited. ${ }^{8,10}$

2. Thyroid-Stimulating Hormone Suppression

A sufficient dose of exogenous thyroid hormone is ad- 
ministered to cause the thyroid gland to stop growing, and hence, so does the nodule. There is no agreement on the efficacy and safety of this method, and the outcome has been questioned when the nodule is larger.

\section{Radioactive Lodine}

The use of radioiodine for benign nodules has had a continuous discussion on its potential to make the nodule malignant. Thyroid absorbs almost all iodine the body takes, and does so with radioactive iodine, ${ }^{131} \mathrm{I}$, if taken by the patient, so the tissue will be destroyed.

\section{Percutaneous Ethanol Ablation}

High concentrated ethanol can be used to destroy the undesired tissue. Before the injection of ethanol, the whole fluid or colloid inside the cyst has to be aspirated using a syringe with the help of normal saline. The amount of ethanol will be a little more than half of aspirated fluid and the retention time is about 2 minutes. ${ }^{5}$

The use of percutaneous ethanol therapy in thyroid diseases, especially in solid nodules, has been limited due to the seepage of ethanol into perinodular tissue, which is the cause of pain and other complications, but remains as an effective method of treating cystic ones. ${ }^{11}$ In addition to the adverse effects of ethanol seepage, the fact of not being able to ablate the undesired tissue in a regular, homogeneous, and reproducible way has been mentioned as the limitation of percutaneous ethanol ablation. ${ }^{12}$

\section{Radiofrequency Ablation}

A new, reportedly safe, minimally invasive and low cost approach to the treatment of benign thyroid nodules that has been introduced in 2006 is to agitate ions in nodule tissue by the oscillations of high-frequency alternating electric current from a thin electrode needle inserted into the center of the nodule. As the ions follow the oscillations, frictional heating ablates nearby tissue. ${ }^{13}$

Reasonable amount of clinical research with follow up periods has proven the efficacy and safety of this method. One point of discussion is the significant thermal pattern that exist around the needle, as the tissue regions very close to it get far more heated than remote tissue which is only heated via thermal conduction of heat generated in closer regions, ${ }^{13,14}$ and certain cases have been reported to experience controllable complications such as pain, voice change, thermal nerve injury, perithyroidal hematomas, skin burn or color change, and nodule rupture..$^{15,16}$

\section{Microwave Ablation}

Another new minimally invasive approach to the treatment of benign thyroid nodules is microwave ablation. A $3 \mathrm{~mm}$ microwave antenna is inserted into the center of the nodule through a $2 \mathrm{~mm}$ incision to ablate it by microwave radiation. This approach of treatment seems to be safe, relatively low in cost, and short in period, yet, there are issues remaining to be resolved, e.g. a fixed-antenna ablation will result in a cylindrical ablated zone despite the fact that most nodules are rather elliptical, and prolonged fixation of the antenna can harm surrounding structures. Further studies have to shed light on the efficacy and safety of this method. ${ }^{3}$

\section{Laser Ablation}

Of special concern to this paper is the application of thermal effects of laser in ablating thyroid nodules. Among the new minimally invasive methods proposed in recent years, laser ablation is shown to possess several advantages, in particular, the ability of defining a regular, homogeneous, and reproducible pattern of ablation. The procedure of laser ablation therapy accompanied by a description of the state of the art in clinical results, efficacy, complications and expenses of this method is provided in this paper.

\section{Mixed Methods}

In order to be more effective, RFAs can be usually preceded by a preparatory aspiration of internal fluid if the nodule is predominantly cystic, which may cause internal bleeding. Yoon et $\mathrm{al}^{17}$ proposed and evaluated a primary ethanol ablation to control this problem before starting RFA, and obtained successful feasibility and safety results, with less complications and shorter treatment time.

\section{Laser Ablation of Thyroid Nodules}

History

The feasibility of the use of laser to ablate benign thyroid nodules was first published in 2000 after it was tested in the late 1990s on 18 resected thyroid glands, with no difficulties, and thereafter, on two volunteers again with no much complication but a mild pain ceasing just after the power was turned off. ${ }^{12}$ The authors suggested to limit the use of this method to only benign cases, which reducing the size of nodule itself alleviates the problem.

Two years later, Døssing et a ${ }^{18}$ published a satisfactory result of laser ablation that they had achieved by illuminating laser to benign thyroid nodules of 16 patients, against a control group of the same size. According to their report, one session of laser therapy with one illuminating fiber resulted in a reduction of about $46 \%$ before 6 months.

Later, Spiezia et $\mathrm{al}^{19}$ published further results confirming the efficacy of this method on 7 patients with autonomous hyperfunctioning thyroid nodules and five patients with compressive nodular goiters. Also, Papini et $\mathrm{al}^{20}$ completed their first introduced method by providing clinical results of volume and symptom reduction of thyroid benign nodules.

After several successful clinical results were published, the American Association of Clinical Endocrinologists/ Associazione Medici Endocrinologi (Italian Association of Clinical Endocrinologists)/European Thyroid Association (AACE-AME-ETA) recommended in 2010 that laser ablation therapy can be a safe and effective option for the treatment of benign thyroid nodules. ${ }^{6}$

\section{Target Patients}

Laser ablation is a considerable option for the treatment of benign thyroid nodules (cold nodules, cystic nodules, 
and autonomously functioning thyroid nodules) in the patients who have:

- significant nodule-related symptoms,

- local pressure symptoms,

- cosmetic complaints,

- obvious outer convex,

- foreign body sensation,

- neck discomfort,

- pain,

- or a recent noticeable increase in the nodule size,

- as well as those who either refuse operation or are not eligible for surgery, or patients that psychologically suffer from frequent clinical examinations. ${ }^{3,6}$

\section{Preparation}

Laser ablation therapy is an outpatient percutaneous procedure. Subjects need to be fasting, with careful local anesthesia, but they can be conscious (with a light sedation administered) and there is no need for the presence of an anesthesiologist, though it is recommended to perform the therapy in a center with an available anesthesiologist and a surgeon as well as an endocrinology unit, and to have emergency care including a defibrillator prepared in the interventional suite. ${ }^{6,9}$

\section{Equipment}

Almost all laser equipment reported to be used in this method are diode lasers $(\mathrm{A}=800-980 \mathrm{~nm})$ or lasers with a medium of the crystals of Nd:YAG (neodymium-doped yttrium aluminum garnet or $\mathrm{Nd}: \mathrm{Y} 3 \mathrm{Al} 5 \mathrm{O} 12)$ operating at $1064 \mathrm{~nm}$ and operation power of about 2-4 W. A 300 to $400 \mathrm{pm}$-diameter plane-cut optic fiber is inserted into the center of the thyroid nodule through the sheath of a 21-gauge Chiba needle, and is locked to be in direct contact with the tissue, not more than the appropriate length, i.e. about 5 to $20 \mathrm{~mm}$. A single fiber will produce a $2 \mathrm{~cm}$ nearly spherical shape of coagulative necrosis, therefore, due to the ellipsoid shape and larger size of the nodules being treated, multiple ablation sessions or multiple fiber insertions arrayed 10 to $18 \mathrm{~mm}$ from each other are often needed.

Most thyroid nodule ablations are guided with real-time ultrasonic images on an auxiliary monitor placed on a tower at the end of the operation table. ${ }^{6,9}$

\section{Procedure}

The procedure mainly requires an operator behind the operation table, and an assistant on the right of it operating the ultrasonic imaging device. The patient will be positioned in supine with hyperextended neck. After administering local anesthesia, based on the size and the shape of the nodule, and the strategy of ablation as if the ablation will be performed in one or more sessions, one to four needles will be inserted along the longitudinal, cranio caudal, and major nodule axes. Fibers may be reinserted in $10 \mathrm{~mm}$ increments to exert the power in further regions, while observing a clearance of $5 \mathrm{~mm}$ from the cranial portion of the nodule. The total energy applied, operation time and number of fibers or sessions are determined according to the shape and size of the nodule. Nodules smaller than 5 $\mathrm{mm}$ in diameter may need only one optic fiber for one session of 6 minutes, and larger ones with the maximum width, thickness and length of 50,35 , and $70 \mathrm{~mm}$ (i.e. with the maximum volume of $60 \mathrm{~mL}$ ) require a combination of multiple fibers placed or pull-backed, higher energy, and a duration extended to 30 minutes. ${ }^{6}$

\section{Follow Up}

When the laser ablation proceeds to its end, patients will be administered with a $20 \mathrm{mg}$ bolus of prednisone to control possible rheumatic and allergic conditions, and an ice pack is pushed slightly on their neck. Then they have to be under observation for about 2 hours in a recovery room, and undergo ultrasonic examination to check if they are clear to leave. On the next 3 days, an oral prednisone therapy consisting of $25 \mathrm{mg} /$ day is administered followed by $12.5 \mathrm{mg}$ /day for another three days and $5 \mathrm{mg} /$ day for 4 days. Besides $30 \mathrm{mg}$ lansoprazole is administered for 10 days. ${ }^{6}$ Follow up examinations are recommended to be done after 1,2, and 6 months, followed by every 6 or 12 month interval examinations depending on the situation of the case. ${ }^{5}$

\section{Efficacy: Selected Clinical Results}

It is probably no exaggeration to state that thermal ablation therapies for benign thyroid nodules are still at their infancy. Nearly all the research in this area has taken place in Italy and Korea.?

This section highlights eight published clinical results that examined the efficacy of laser ablation on patients with different nodule type, size, and background, in different centers, with different methods, and with different equipment.

Gambelunghe et $\mathrm{al}^{21}$ designed a randomized controlled study on 26 patients who had either a high risk of surgery or compressive symptoms due to benign thyroid nodules. After 2 weeks, the intervention group demonstrated a reduction of $22 \%$ in the volume of their nodule, which yielded to $44 \%$ after 30 weeks. They also found evidence of a positive correlation between the amount of energy exerted and the reduction volume.

Døssing et $\mathrm{a}^{22}$ compared the efficacy of one interstitial laser photocoagulation session with one radioiodine $\left({ }^{131} \mathrm{I}\right)$ dose on two randomized groups of 15 patients with subclinical or mild hyperthyroidism. Comparing the results at baseline, 1, 3 and 6 months, they observed the normalization of serum TSH in 7 out of 14 patients in the interstitial laser photocoagulation group and in all 15 patients in the radioiodine group. They also found a nodule volume reduction of about $44 \%$ in the first and about $47 \%$ in the latter group. ${ }^{22}$

In a comparative study on 62 randomly grouped patients with solid benign nodules, Papini et $\mathrm{a}^{23}$ examined the results of a 10 minutes of $1.064 \mathrm{pm} 3 \mathrm{~W}$ radiation of 
neodymium yttrium-aluminum-garnet laser, and also the effect of a dose of levothyroxine suppressive therapy against a non-treated control group. They found significant reduction (about $42.7 \%$ ) of nodule volume in group 1 , no significant shrinkage in group 2 , and non-significant increase in the control group..$^{23}$

Valcavi et $\mathrm{a}^{24}$ for the first time conducted a 3-year follow up to examine the results of laser ablation over a group of 122 patients with benign cold thyroid solitary nodules or a dominant nodule within a normo-functioning multinodular goiter. Three years after PLA, they observed a nodule volume decrease of about $47.8 \%$ (with a deviation of $33.1 \%$ ), improved symptoms in $73.0 \%$, and improved cosmetic signs in $71.3 \%$. They reported also few cases of laryngeal dysfunction, voice changes and hypothyroidism. ${ }^{24}$ Amabile et $\mathrm{al}^{25}$ tested the effect of one to three cycles of laser ablation with an interval of 1 month on 51 patients with non-functioning thyroid nodules and 26 patients with hyperfunctioning thyroid nodules. They observed that a significant nodule volume reduction occurred in both groups, $87 \%$ of whom were cured with no major complications, but reported some mild pain, vasovagal reaction, and fever.

Døssing et $\mathrm{al}^{26}$ published a 10 year result of their follow up after laser ablation therapy on 78 patients with solitary benign thyroid nodules, which shows a reduction with a median of $51 \%$ in nodule volume. Twenty-one patients retired from the follow up earlier due to surgery, but side effects were limited to mild local pain.

Døssing et $\mathrm{al}^{27}$ examined the effect of laser ablation on improving the results of cystic benign nodule aspiration on 44 randomly grouped patients. Six months after the aspiration session, they achieved a cyst volume less than $1 \mathrm{~mL}$ in $68 \%$ of patients that underwent an additional session of laser ablation, and only $18 \%$ of the control group with no laser therapy. Also, the size of the solid part of the nodules reduced from 1.8 to $1.0 \mathrm{~mL}$ by the laser ablation, while it had no significant change in the control group.

Achille et $\mathrm{al}^{28}$ evaluated laser ablation therapy on $45 \mathrm{pa}-$ tients complaining of either pressure or cosmetic distress due to benign solid (max fluid 20\%) thyroid nodules, between October 2009 and January 2011. They used Nd:YAG laser at $1064 \mathrm{~nm} 3 \mathrm{~W}$ power with varying durations. Evaluations were done at baseline, 6 and 12 months. Their outcomes showed a reduction of about $20 \mathrm{~mL}$ at 12 months $(84 \% \pm 13 \%)$, with resolved cosmetic signs in $87 \%$ and resolved pressure symptoms in $88 \%$. They also reported one case of rare complication, i.e. voice change.

\section{Side Effects}

The reported complications of laser ablation have not been serious. Cakir et $\mathrm{a}^{29}$ observed slight intra-operation ear-pain on the side of the ablation and subsequent pain in swallowing for a few days in 4 of their 12 patients that ceased with paracetamol. Studies with larger samples and follow-ups have shown some controlled intranodular bleeding during needle placement that did not termi- nate the procedure. Thyroid pericapsular bleeding, vagal symptoms with bradycardia, voice change, and cough each appeared in about $2 \%$ of patients. Three percent of them experienced fluid leakage into the neck muscle fascia, and 5\% pseudocyst transformation. Six months after the ablation, the rate of thyroid dysfunction among the patients were about $3 \%$ with no clue if it has been due to laser ablation. ${ }^{6}$ Other adverse effects such as dysphony, hematoma burns and transient stridor have been quite rare. ${ }^{9}$ In a recent report, Achille et $\mathrm{a}^{28}$ observed that only one patient out of 40 patients experienced dysphonia, who found his normal voice after 8 weeks of care, one other patient experienced intense local pain, another experienced hyperpyrexia, but mild to moderate local pain occurred in 12 of them.

\section{Cost Analysis}

There are quite few published financial analyses of the expenses of laser ablation, but it is mentioned to be less expensive than other methods. Gharib et $\mathrm{al}^{9}$ provided some price list data about the equipment used in this method with some variations in attributes, but no analysis of the total price each operation may save or impose has been provided. Longo et $\mathrm{al}^{4}$ tried to figure out the financial effect of provisioning laser ablation operations on the financial balance of a hospital. Although they found that every operation can be considered as a financial loss to the hospital, they assessed continuing to perform this method as a reputation to it, which is difficult to describe in economic scales. Besides, they suggested they had not enough information as if the hospital would have provisioned the other alternative methods.

\section{Comparison}

Ethanol ablation therapy has been known as the first-line treatment for benign thyroid nodules, especially in cystic ones. ${ }^{30}$ As the solid component of a nodule increases, however, ethanol ablation will be less effective even with repeated treatments. Thermal ablation methods have shown better outcomes when the nodule was not totally cystic, but predominantly cystic. Ethanol has not been reported to be successful in ablation of the solid component, which has been known to cause the recurrences observed a few months later. When a nodule is categorized as predominantly solid, ethanol ablation has not been considered as an appropriate method, ${ }^{5}$ and it has been completely abandoned for the solid ones. ${ }^{28}$

Among thermal ablation therapies for thyroid benign ablation, RFA has shown a little superiority in results to laser ablation method. ${ }^{15,31} \mathrm{Ha}$ et $\mathrm{al}^{1}$ reviewed 33 published clinical results that have evaluated either radiofrequency or laser ablation methods. They concluded that a single electrode radiofrequency treatment would result in better (76.1\%) reduction volumes than a single fiber laser treatment (49.9\%). They suggested this superiority could be a result of the moving-electrode technic in radiofrequency, while managing multiple fibers in thyroid could be more 
difficult. Besides, they suggested that radiofrequency approach has been better in the ablation of marginal components which may have prevented marginal regrowth. They concluded that more randomized clinical research would be required to decide about the actual efficacy, cost, safety, and long term efficacy of both methods.

\section{Conclusion}

Non-surgical approaches to the treatment of benign thyroid nodules have been largely considered in recent years. Laser ablation is one of the newest thermal ablation methods that has shown a reasonable efficacy with quite little complications, although there are important questions on how to improve the outcomes by producing a heating region similar to the shape of undesired tissue. It is not yet the time to decide definitively about the possible superiorities among the three thermal ablation approaches, since a required amount of outcomes, especially long-term follow-up results, has not been accumulated. Different types of benign thyroid nodules have to be treated by controlled and randomized examinations, well established selection criteria have to illuminate the best treatment method for each patient, and technological improvements must facilitate nodule ablations with desired shapes. Laser ablation is such an inexpensive, effective, safe, and minimally invasive method that can be an appropriate alternative for debulking benign thyroid nodules.

\section{References}

1. Ha EJ, BaekJH, Kim KW, et al. Comparative efficacy of radiofrequency and laser ablation for the treatment of benign thyroid nodules: systematic review including traditional pooling and Bayesian network metaanalysis. J Clin Endocrinol Metab. 2015;100(5):19031911. doi:10.1210/jc.2014-4077

2. Andrioli M, Carzaniga C, Persani L. Standardized ultrasound report for thyroid nodules: the endocrinologist's viewpoint. Eur Thyroid J. 2013;2(1):37-48. doi:10.1159/000347144

3. Feng B, Liang P. Microwave Ablation of Benign Thyroid Nodules. Microwave Ablation Treatment of Solid Tumors; 2015:205-216. doi:10.1007/978-94017-9315-5_19

4. Longo M, Cassoli IP, Fugazzola L, Vannucchi G, Lanzoni M, Castaldi S. Feasibility study for the introduction of a new treatment method for benign thyroid nodules in a teaching and research hospital. J Eval Clin Pract. 2014;20(5):617-621. doi:10.1111/ jep. 12177

5. Ha EJ, Baek JH. Advances in nonsurgical treatment of benign thyroid nodules. Future Oncol. 2014;10(8):1399-1405. doi:10.2217/fon.14.59

6. Baek JH, Lee JH, Valcavi R, Pacella CM, Rhim $\mathrm{H}$, Na DG. Thermal ablation for benign thyroid nodules: radiofrequency and laser. Korean J Radiol. 2011;12(5):525-540. doi:10.3348/kjr.2011.12.5.525

7. Lee M-T, Wang C-Y. Radiofrequency Ablation in Nodular Thyroid Diseases. J Med Ultrasound. 2013;21(2):62-70. doi:10.1016/j.jmu.2013.04.006

8. Døssing H, Bennedbæk FN, Hegedüs L. Effect of ultrasound-guided interstitial laser photocoagulation on benign solitary solid cold thyroid nodules: one versus three treatments. Thyroid. 2006;16(8):763-768. doi:10.1089/thy.2006.16.763

9. Gharib H, Hegedüs L, Pacella CM, Baek JH, Papini E. Nonsurgical, image-guided, minimally invasive therapy for thyroid nodules. J Clin Endocrinol Metab. 2013;98(10):3949-3957. doi:10.1210/jc.2013-1806

10. Ha EJ, Baek JH, Lee JH, et al. Radiofrequency ablation of benign thyroid nodules does not affect thyroid function in patients with previous lobectomy. Thyroid. 2013;23(3):289-293. doi:10.1089/thy.2012.0171

11. Faggiano A, Ramundo V, Assanti A, et al. Thyroid nodules treated with percutaneous radiofrequency thermal ablation: a comparative study. The J Clin Endocrinol Metab. 2012;97(12):4439-4445. doi:10.1210/jc.2012-2251

12. PacellaCM,BizzarriG, GuglielmiR,etal.Thyroidtissue: us-guided percutaneous interstitial laser ablation-a feasibility study 1. Radiology. 2000;217(3):673-677. doi:10.1148/radiology.217.3.r00dc09673

13. De Bernardi IC, Floridi C, Muollo A, et al. Vascular and interventional radiology radiofrequency ablation of benign thyroid nodules and recurrent thyroid cancers: literature review. La Radiologia Medica. 2014;119(7):512-520. doi:10.1007/s11547-014-04112

14. Lim HK, Lee JH, Ha EJ, Sung JY, Kim JK, Baek JH. Radiofrequency ablation of benign non-functioning thyroid nodules: 4-year follow-up results for 111 patients. Eur Radiol. 2013;23(4):1044-1049. doi:10.1007/s00330-012-2671-3

15. Shin JH, Baek JH, Ha EJ, Lee JH. Radiofrequency ablation of thyroid nodules: basic principles and clinical application. Int J Endocrinol. 2012;2012: 919650. doi:10.1155/2012/919650

16. Wong K-P, Lang $\mathrm{BH}-\mathrm{H}$. Use of radiofrequency ablation in benign thyroid nodules: a literature review and updates. Int J Endocrinol. 2013;2013: 428363. doi:10.1155/2013/428363

17. Yoon H, Baek J, Lee J, et al. Combination therapy consisting of ethanol and radiofrequency ablation for predominantly cystic thyroid nodules. Am J Neuroradiol. 2014;35(3):582-586. doi:10.3174/ajnr. a3701

18. Døssing H, Bennedbæk FN, Karstrup S, Hegedüs L. Benign solitary solid cold thyroid nodules: US-guided interstitial laser photocoagulation-initial experience 1. Radiology. 2002;225(1):53-57. doi:10.1148/ radiol.2251011042

19. Spiezia S, Vitale G, Di Somma C, et al. Ultrasound-guided laser thermal ablation in the treatment of autonomous hyperfunctioning thyroid nodules and compressive nontoxic nodular goiter. Thyroid. 2003;13(10):941-947. 
doi:10.1089/105072503322511346

20. Papini E, Guglielmi R, Bizzarri G, Pacella CM. Ultrasound-guided laser thermal ablation for treatment of benign thyroid nodules. Endocr Pract. 2004;10(3):276-283. doi:10.4158/ep.10.3.276

21. Gambelunghe G, Fatone C, Ranchelli A, et al. A randomized controlled trial to evaluate the efficacy of ultrasound-guided laser photocoagulation for treatment of benign thyroid nodules. J Endocrinol Invest. 2006;29(9):RC23-RC26. doi:10.1007/ bf03347368

22. Døssing H, Bennedbæk FN, Bonnema SJ, Grupe $\mathrm{P}$, Hegedüs L. Randomized prospective study comparing a single radioiodine dose and a single laser therapy session in autonomously functioning thyroid nodules. Eur J Endocrin. 2007;157(1):95-100. doi:10.1530/eje-07-0094

23. Papini E, Guglielmi R, Bizzarri G, et al. Treatment of benign cold thyroid nodules: a randomized clinical trial of percutaneous laser ablation versus levothyroxine therapy or follow-up. Thyroid. 2007;17(3):229-235. doi:10.1089/thy.2006.0204

24. Valcavi R, Riganti F, Bertani A, Formisano D, Pacella CM. Percutaneous laser ablation of cold benign thyroid nodules: a 3-year follow-up study in 122 patients. Thyroid. 2010;20(11):1253-1261. doi:10.1089/thy.2010.0189

25. Amabile G, Rotondi M, Pirali B, et al. Interstitial laser photocoagulation for benign thyroid nodules: time to treat large nodules. Lasers Surg Med. 2011;43(8):797803. doi:10.1002/lsm.21114
26. Døssing H, Bennedbæk FN, Hegedüs L. Long-term outcome following interstitial laser photocoagulation of benign cold thyroid nodules. Eur J Endocrin. 2011;165(1):123-128. doi:10.1530/eje-11-0220

27. Døssing H, Bennedbæk FN, Hegedüs L. Interstitial laser photocoagulation (ILP) of benign cystic thyroid nodules-a prospective randomized trial. J Clin Endocrinol Metab. 2013;98(7):E1213-E1217. doi:10.1210/jc.2013-1503

28. Achille G, Zizzi S, Di Stasio E, Grammatica A, Grammatica L. Ultrasound-guided percutaneous laser ablation (LA) in treating symptomatic solid benign thyroid nodules: Our experience in 45 patients. Head Neck. 2014. doi:10.1002/hed.23957

29. Cakir B, Topaloglu O, Gul K, et al. Effects of percutaneous laser ablation treatment in benign solitary thyroid nodules on nodule volume, thyroglobulin and anti-thyroglobulin levels, and cytopathology of nodule in $1 \mathrm{yr}$ follow-up. $J$ Endocrinol Invest. 2006;29(10):876-884. doi:10.1007/ bf03349190

30. Sung JY, Baek JH, Kim KS, et al. Single-session treatment of benign cystic thyroid nodules with ethanol versus radiofrequency ablation: a prospective randomized study. Radiology. 2013;269(1):293-300. doi:10.1148/radiol.13122134

31. Na DG, Lee JH, Jung SL, et al. Radiofrequency ablation of benign thyroid nodules and recurrent thyroid cancers: consensus statement and recommendations. Korean J Radiol. 2012;13(2):117-125. doi:10.3348/ kjr.2012.13.2.117 